\title{
Household and individual level risk factors associated with declining malaria incidence in Meghalaya, India: implications for malaria elimination in low-endemic settings
}

\author{
Rajiv Sarkar ${ }^{1,2^{*}} \mathbb{D}$, Anne Kessler ${ }^{3}$, Bandapkupar Mawkhlieng², Steven A. Sullivan ${ }^{3}$, Mark L. Wilson ${ }^{4}$,
} Jane M. Carlton ${ }^{3,5}$ and Sandra Albert ${ }^{1,2}$

\begin{abstract}
Background: A detailed analysis of household and individual level Plasmodium infection patterns in two lowendemic districts of Meghalaya was undertaken to better understand the epidemiology of malaria in northeast India.

Methods: Socio-demographic and behavioural information from residents (aged 1-69 years) of households were collected through pre-tested, questionnaire conducted in 2018 and 2019. Blood samples collected from participants were tested for Plasmodium falciparum and/or Plasmodium vivax infection using rapid diagnostic test, microscopy and PCR. Plasma samples from a subset of participants were analysed for antibodies against thirteen P. falciparum and four P. vivax antigens. Associations between household and individual level risk factors, and Plasmodium infections were evaluated using multilevel logistic regression models.
\end{abstract}

Results: A total of 2753 individuals from 827 households were enrolled in 2018, and 834 individuals from 222 households were enrolled in 2019. Of them, 33 (1.2\%) were positive by PCR for P. falciparum in 2018 and none were positive for P. vivax. In 2019, no PCR-positive individuals were detected. All, but one, infections were asymptomatic; all 33 infections were sub-microscopic. Reported history of malaria in the past 12 months $(\mathrm{OR}=8.84)$ and history of travel in the past 14 days $(O R=10.06)$ were significantly associated with Plasmodium infection. A significant trend of increased seropositivity with age was noted for all 17 antigens. Although adults ( $\geq 18$ years) consistently had the highest seropositivity rates, a sizeable proportion of under-five children were also found to be seropositive. Almost all individuals (99.4\%) reported sleeping under an insecticide-treated bed-net, and household indoor residual spray coverage in the 12 months preceding the survey was low (23\%). Most participants correctly identified common signs and symptoms of malaria, i.e., fever (96.4\%), headache (71.2\%), chills (83.2\%) and body-ache (61.8\%). Almost all participants (94.3\%) used government-provided services for treatment of malaria.

Conclusion: This study explored the epidemiology of malaria in two communities in Meghalaya, India, in the context of declining transmission. The presence of widespread asymptomatic infections and seropositivity among under-five children suggest that low-level Plasmodium transmission persists in this region. Implications of the study findings for malaria elimination efforts in low-transmission settings are discussed.

*Correspondence: rajiv.sarkar@iiphs.org

${ }^{1}$ Indian Institute of Public Health - Shillong, Shillong, Meghalaya 793001

India

Full list of author information is available at the end of the article original author(s) and the source, provide a link to the Creative Commons licence, and indicate if changes were made. The images or other third party material in this article are included in the article's Creative Commons licence, unless indicated otherwise in a credit line to the material. If material is not included in the article's Creative Commons licence and your intended use is not permitted by statutory regulation or exceeds the permitted use, you will need to obtain permission directly from the copyright holder. To view a copy of this licence, visit http://creativecommons.org/licenses/by/4.0/. The Creative Commons Public Domain Dedication waiver (http://creativeco mmons.org/publicdomain/zero/1.0/) applies to the data made available in this article, unless otherwise stated in a credit line to the data. 
Keywords: Asymptomatic infection, Transmission intensity, Malaria elimination, Northeast India

\section{Background}

Malaria continues to be a major public health problem globally with an estimated 229 million cases reported from 87 endemic countries [1]. India has the world's largest population at risk of malaria, with an estimated 162.5 million people living in high-transmission areas $[2,3]$. Despite this, India has achieved a steady decline in the annual incidence of malaria from around 20 million in 2000 to 6 million in 2019, i.e., an absolute reduction of $73 \%[1]$.

In 2016, India launched the National Framework for Malaria Elimination with the ambitious goals of eliminating malaria from the country by 2030 , maintaining malaria free status, and preventing reintroduction of infection in areas where transmission interruption has been achieved [4]. To achieve these goals, a five-year National Strategic Plan for Malaria Elimination was also launched in 2017 [5]. However, socio-cultural and behavioural beliefs and practices, undetected transmission from asymptomatic individuals, importation of infection from endemic areas, poor disease surveillance, resistance to antimalarial drugs and insecticides, and healthcare delivery and access issues may adversely impact the elimination efforts [6-8].

Even though the northeast region (NER) comprises about $4 \%$ of India's population, it accounted for around $15 \%$ of the country's Plasmodium falciparum cases and $22 \%$ of the malaria deaths reported in 2019 [9]. Malaria incidence over the past decade has declined more slowly in the NER relative to the rest of the subcontinent [2]. This lag in declining incidence is partly due to the unique ecological and socio-cultural conditions of the NER, inhospitable terrain, poor road conditions and inadequate healthcare infrastructure, all of which may have contributed to the relatively high malaria incidence, until recently [3]. This is particularly true in the state of Meghalaya where incidence increased from 2012 to 2015, and only began to decline after 2016 [10, 11]. The reasons for the observed delayed decline in malaria incidence in Meghalaya are unclear but could be related to the first wide-spread distribution of long-lasting insecticidal nets (LLINs) in the endemic communities not occurring until 2016 [11].

Information on malaria patterns in Meghalaya is limited to unpublished government reports and a recent cross-sectional survey in two districts [11]. The later characterised village-level prevalence of Plasmodium infection during 2018-2019 in 21 villages, summarised village-level risk factors for infection, and identified 13
Anopheles mosquito species as potential vectors in a subset of villages [11]. To further understand the epidemiology of malaria in Meghalaya, the study presented here undertook detailed analysis of household and individual level Plasmodium infection patterns in the same two lowendemic communities in 2018-2019, evaluated social and behavioural risk factors for infection, and explored patterns of Plasmodium antigen-specific antibodies in the population.

\section{Methods}

\section{Study area and population}

This study was conducted in two districts of Meghalaya: West Khasi Hills $(\mathrm{KH})$ and West Jaintia Hills $(\mathrm{JH})$. Meghalaya is a hilly and mountainous state in northeast India, located between Assam and Bangladesh (Fig. 1), with a population of about 3 million, mostly indigenous [12]. More than $75 \%$ of Meghalaya is forested [13]. The economy is predominantly agrarian; mixed farming (growing crops together with raising livestock) is a common practice [14]. The climate is the wettest in India especially during the May-September rainy season. With $23-28{ }^{\circ} \mathrm{C}$ temperatures and high relative humidity $(>70 \%$ ) the conditions are conducive for mosquito breeding and perennial transmission. Between 2012 and 2015, the number of malaria cases and deaths in Meghalaya increased steadily, but seems to have generally declined from 2016 [10], although the rate of decline varied between and within districts [11].

\section{Data collected during community surveys}

Socio-demographic and behavioural information was collected from residents (aged 1-69 years) of households in the $\mathrm{JH}$ and $\mathrm{KH}$ from April to November 2018 and again from May to September 2019. Details of the sampling design and methods have been described elsewhere [11]. Briefly, a total of 21 villages were selected for the study based on reported prior Plasmodium infections (both high and low prevalence), representation across primary health centres (PHC) and health sub-centres in the study area and location. A random sample of households from each village (selected based on probability proportion to size technique) were consented and enrolled. A household survey was administered to one resident of each participating household, usually the 'head of household' that included questions on family size, source of water supply, building materials for roofs and walls, presence of electricity, toilets, animals and malaria prevention methods 


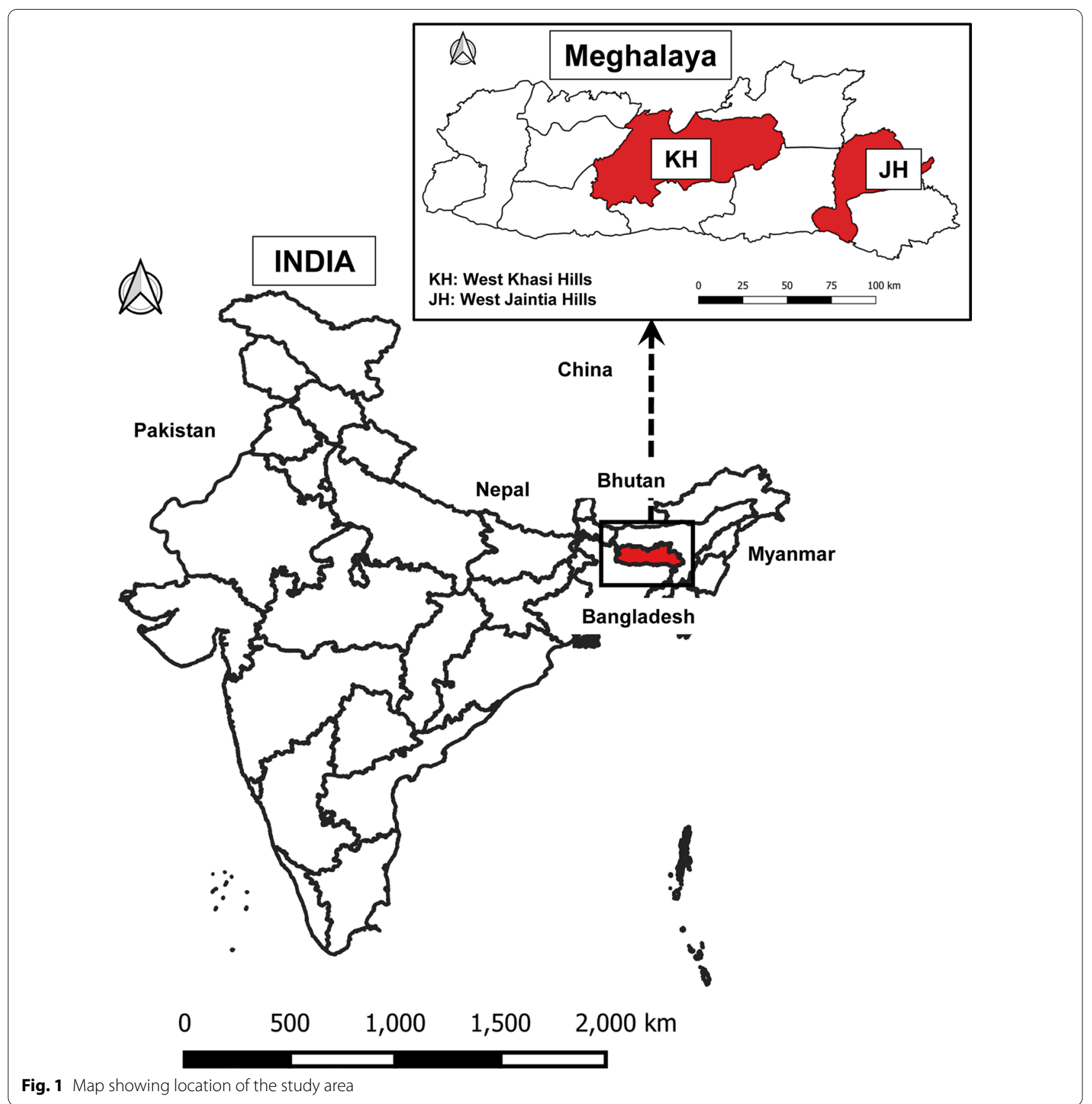

(insecticide-treated nets [ITN], repellents, coils, DDT spraying). In addition, the household members were administered individual surveys during which they were asked mostly close-ended questions in their local language (Khasi, Pnar) to obtain information on age, gender, education, occupation, knowledge of malaria, health history (malaria episodes [preceding year], fever episodes [preceding $48 \mathrm{~h}$ ]), travel history (past two weeks) and malaria prevention methods. Malaria risk behaviours and practices were also surveyed. Parents or caretakers responded on behalf of their children.

\section{Blood sample collection and Plasmodium detection}

Details of the blood sample collection and Plasmodium detection methods have been described elsewhere [11]. Briefly, a small blood volume was taken by finger prick, and point-of-care detection of $P$. falciparum and/or $P$. vivax infections was determined by a bivalent rapid diagnostic test (RDT; FalciVax) and an ultra-sensitive RDT 
(Abbott Alere). Blood smears were also collected, fixed in methanol and Giemsa-stained prior to qualitative and quantitative evaluation by light microscopy. From the small blood volume, blood components were separated by centrifugation into plasma and a red blood cell (RBC) pellet and stored at $-80^{\circ} \mathrm{C}$ until assayed.

Species-specific Plasmodium infections were detected by PCR amplification of concentrated DNA extracted from microvette RBC pellets using a single-step PCR targeting Pfr364 (for P. falciparum) and Pvr47 (for P. vivax) genomes, respectively [15], as previously described [11]. A positive Plasmodium infection was indicated based upon RDT results and/or PCR results; no infections were detected by microscopy.

\section{Antibody quantification by Luminex MAGPIX}

Seventeen recombinant $P$. falciparum and $P$. vivax proteins and/or peptides were coupled to unique Luminex Magplex magnetic microspheres and used in a multiplexed, bead-based assay to quantify host IgG antibodies as previously described [16]. Plasma samples from a total of 264 study participants were assayed. The samples were selected through a stratified random sampling technique, considering village as the strata; approximately $10 \%$ of the plasma samples collected in each village were tested. Plasma isolated from the small blood volumes collected by finger prick from the participants were prepared at $1 / 200$ in a buffer of PBS, $0.05 \%$ Tween, $0.5 \%$ BSA, $0.02 \%$ sodium azide, $0.1 \%$ casein, $0.5 \%$ PVA, $0.5 \%$ PVP, and $E$. coli extract. All samples were assayed singularly with positive controls, naïve sample pools, and blanks run in duplicate or triplicate according to standardized procedures [17]. Plates were analysed on a Luminex MAGPIX, and $\mathrm{xPONENT}$ software was used for data acquisition (Luminex Corp., Austin, TX).

\section{Statistical analysis}

Data were collected and managed using REDCap electronic data capture tools $[18,19]$ hosted at New York University and analysed using Stata software, version 14.2 for Windows (StataCorp, College Station, Texas). Data analyses were conducted using a complete-case approach, whereby participants with missing data for relevant variables were excluded. Summary statistics for continuous variables are presented as mean and standard deviation (SD) or median and interquartile range (IQR, 25th-75th percentile), depending on the distribution of data and as numbers and percentages (\%) for categorical variables. The prevalence of Plasmodium infection, along with the 95\% confidence interval (CI), was calculated using the Taylor linearized method that accounts for the clustered data-structure [20]. Associations between household and individual level socio-demographic, environmental and behavioural risk factors, and Plasmodium infections were evaluated using multilevel logistic regression models with exchangeable correlation matrix, considering village and household as grouping variables and reported as odds ratios (OR) with 95\% CIs.

\section{Antibody data analysis}

Net mean fluorescence intensity (MFI) (net $\mathrm{MFI}_{\mathrm{Ag}}=$ raw $\mathrm{MFI}_{\mathrm{Ag}}$ - background $\mathrm{MFI}_{\mathrm{Ag}}$ ) where background $\mathrm{MFI}_{\mathrm{Ag}}$ is the mean MFI of a given antigen in the blank wells was calculated for each antigen in each sample assayed. The seropositive threshold for each antigen was defined as mean net $\mathrm{MFI}_{\text {negative pool }}$ plus three standard deviations. The number and proportion of individuals seropositive for each antigen was tabulated for three age categories: children (1-7 years), adolescents (8-17 years), and adults ( $\geq 18$ years). Differences in the proportion of seropositive individuals across the three age categories was determined by using the chi-square test for trend. The net $\mathrm{MFI}_{\mathrm{Ag}}$ values from seropositive individuals were normalised with respect to the corresponding seropositive threshold value to generate a relative MFI value for comparison of response magnitudes (e.g., normalised relative values greater than one were considered seropositive for IgG to the respective antigen). The median (IQR) relative MFI values were determined for each antigen across all age groups, and differences in the relative magnitude of response across age groups was tested using a nonparametric test for trend across ordered groups [21].

\section{Ethical approval}

Permission to undertake the study was obtained from the Institutional Review Board at New York University, New York, NY, USA and the University Research Ethics Committee of Martin Luther Christian University, Shillong, Meghalaya, India. Written informed consent was obtained from all adult participants ( $\geq 18$ years of age). Assent was obtained for participants aged 7-17 years, in addition to the parental consent.

\section{Results}

From 21 villages surveyed in $\mathrm{JH}(\mathrm{N}=9)$ and $\mathrm{KH}$ $(\mathrm{N}=12)$ that represented 9306 residents from 1688 households, a total of 3017 (32.4\%) individuals were approached for participation; 2753 individuals (29.6\%) living in 820 households (48.6\%) were enrolled in the study during 2018. In 2019, 222 households (13.2\%) and 834 people (9\%) from these villages were enrolled. The age and gender distribution of the total population of the two districts and that of the study participants is presented in Fig. 2. Compared to the age and gender distribution of the population at the district-level, the 


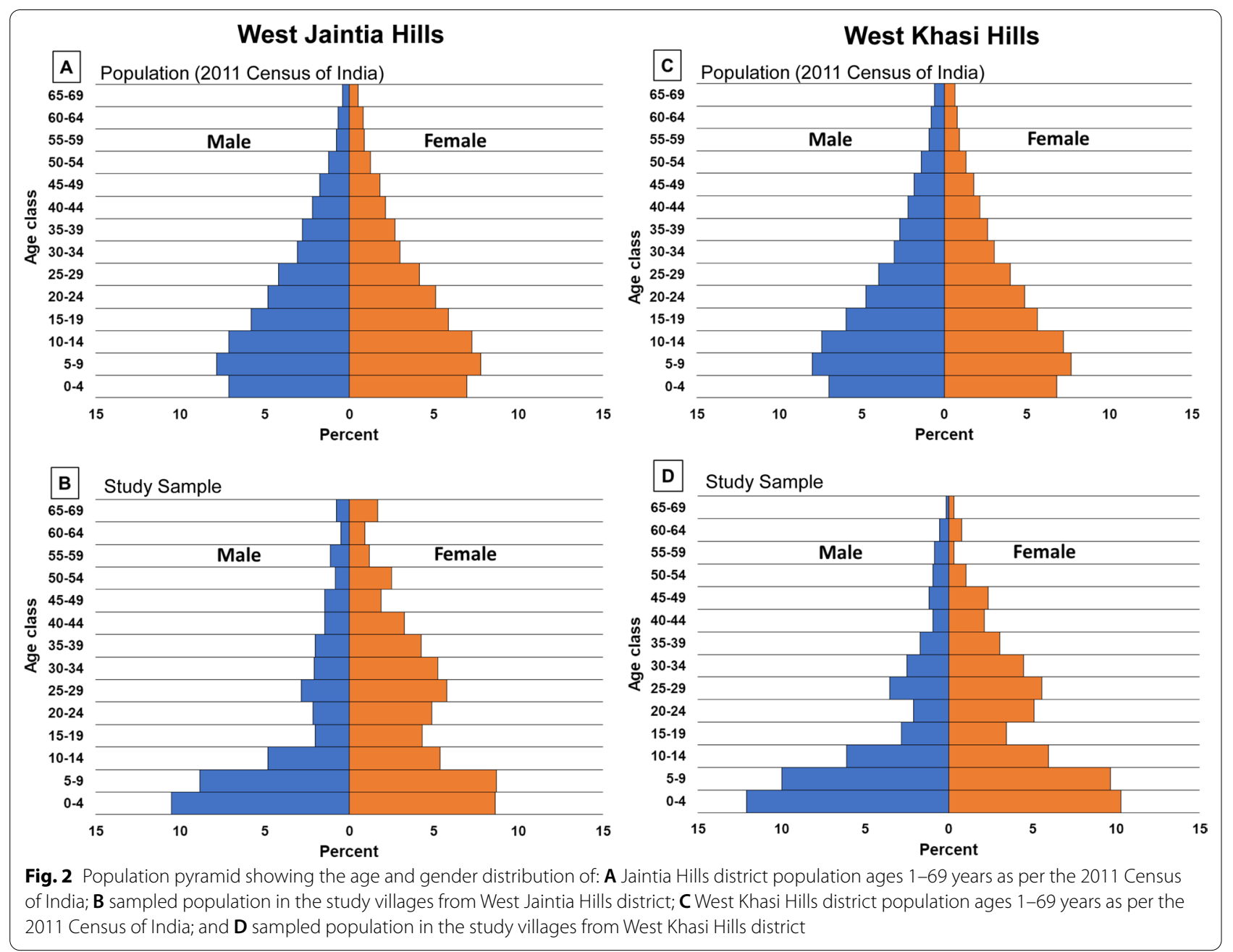

study participants had greater representation of children and female participants.

Blood from microvette samples during 2018 was available for testing from 1463 of the 1467 (99.7\%) participants in $\mathrm{JH}$, and 1234 of the $1286(98.3 \%) \mathrm{KH}$ participants. In 2018, 33 of 2697 study participants (1.2\%, 95\% CI $0.5-3.2 \%)$ were positive by PCR for $P$. falciparum; none of the participants tested positive for P. vivax. One (3\%) of the 33 PCR-positive samples was also positive by RDT (both bivalent and ultra-sensitive). The prevalence of $P$. falciparum infection was similar in $\mathrm{JH}(1.1 \%, 95 \% \mathrm{CI} 0.2-7.2 \%)$ and $\mathrm{KH}(1.4 \%$, $95 \%$ CI $0.5-3.8 \%)$. In 2019, none of 834 blood samples $(0 \%)$ were positive for either Plasmodium species, including samples from 18 PCR-positive individuals from the 2018 survey. For this reason, analysis of risk factors for $P$. falciparum was undertaken solely for 2018.

\section{Characteristics of the 2018 study population Household level characteristics}

The household level characteristics, aggregated by village, have been described elsewhere [11]. Briefly, the average (SD) household comprised of 5.6 (2.1) individuals. Brick (31.1\%) was the commonest building material for the side walls, while the roofs were commonly made of tin (89.4\%). More than two-thirds (68.1\%) of the participating households had electricity and three-fourths (77.7\%) had piped water supplied through indoor plumbing. A functional toilet was available in $88.2 \%$ of households, and almost all households (98.8\%) with a functional toilet reported it being used all the time by household members. More than half $(60.7 \%)$ of the respondent households had access to a mobile phone, and those with access reported mostly using it (84.7\%) during the time of illness. More households in $\mathrm{JH}$ vs. $\mathrm{KH}$ had mobile phones $(73.1 \%$ vs. $44.2 \%)$ and reported using them during sickness $(62.6 \%$ vs. $36.4 \%)$. Animals were present in 
more than half $(59.3 \%)$ of households, including poultry $(52.0 \%)$ and pigs $(27.7 \%)$; more than a third (38.3\%) reported keeping animals inside the house.

\section{Individual level characteristics}

The mean (SD) age of participants was 20.8 (17.2) years. Slightly more females $(56.5 \%)$ than males participated in the study. Of the adult participants ( $\geq 18$ years), a majority $(47.6 \%)$ had less than primary education (no formal education or completed preschool/kindergarten). Most participants were either students $(35.8 \%)$ or engaged in agriculture-related activity (27.5\%). Malaria diagnosis within the past 12 months was reported by only $3.6 \%$ of the participants; $2 \%$ of participants reported a history of travel outside of the village in the last 14 days. Around $5 \%$ of the participants reported staying in the field for one or more nights, with a mean (SD) of 6.9 (3.0) days. A large majority $(86.2 \%)$ reported using ITNs while staying in the field. Most participants had knowledge of the common signs and symptoms of malaria, i.e., fever (96.4\%), headache (71.2\%), chills (83.2\%) and body-ache (61.8\%). Almost everyone (94.3\%) preferred to seek treatment from government healthcare facility or community health worker (Accredited Social Health Activist or ASHA), if diagnosed with malaria.

The individual level socio-demographic characteristics of the study participants are presented in Table 1 . The age and gender distribution of participants were similar between the two study areas. More adult participants in $\mathrm{JH}(55.7 \%)$ had below primary education than in $\mathrm{KH}(37 \%)$. A greater proportion of participants in $\mathrm{KH}$ reported being diagnosed with malaria in the past 12 months (6.5\% vs $1.1 \%)$. On the other hand, a greater proportion of participants in $\mathrm{JH}$ reported staying overnight in the field for one or more days (7.9\% vs $1.7 \%$ ). Also, participants from $\mathrm{JH}$ (7.3 [3.0]) tended to stay longer in the field than those in $\mathrm{KH}$ (4.8 [1.9]), although the proportion of participants using ITNs while staying in the field was greater (94\%) in JH than in $\mathrm{KH}(45.5 \%)$. The majority of participants in both study areas was correctly able to recall the signs and symptoms of malaria, although a larger proportion of respondents from $\mathrm{JH}$ (99.8\%), as opposed to $\mathrm{KH}(88.1 \%)$, preferred to seek treatment from government healthcare facility or the ASHA if diagnosed with malaria.

\section{Risk factors of malaria infection}

The household and individual level risk factors for Plasmodium infections were assessed separately for $\mathrm{JH}$ and KH. A total of 2697 individuals from 819 households for whom a PCR-test result for Plasmodium infection was available were included in the analysis (1463 from 468 households in JH, and 1234 from 351 households in $\mathrm{KH}$ ).

\section{Household level risk factors for Plasmodium infection}

A variety of potential household characteristics and household level behaviours were analysed as risk for Plasmodium infection in individual household members (Table 2). These included presence of electricity and mobile phones, house roof and wall construction materials, presence of animals, anti-mosquito prevention measures, including indoor residual spraying. None of the household level factors were found to significantly predict the risk of Plasmodium infection in the study population.

\section{Individual level risk factors for Plasmodium infection}

The individual level risk factors for Plasmodium infection were also analysed (Table 3). A reported history of malaria in the past 12 months $(\mathrm{OR}=8.84, P=0.046)$ was significantly associated with Plasmodium infection in $\mathrm{JH}$ and history of travel in the past 14 days $(\mathrm{OR}=10.06, \quad P=0.008)$ was significantly associated with Plasmodium infection in $\mathrm{KH}$. None of the other factors were significantly associated with risk of Plasmodium infection in either of the two study districts.

\section{Presence and relative magnitude of anti-P. falciparum and anti-P. vivax antibodies in a subset of study participants}

The number and proportion of seropositive individuals in each age category are listed by antigen/antibody in Table 4. For each antigen assayed, two or more individuals in each age category were found to be seropositive. The proportion of seropositive individuals by age group was significantly different for all 17 antigens, and the greatest proportion of seropositive individuals was consistently observed in the adult age category.

The relative magnitude of antibody detected was significantly different across age groups for eight of the 13 $P$. falciparum antigens assayed: PfAMA1 $(P<0.001)$, PfEBA175 $(P<0.001)$, PfEBA181 $(P=0.001), \quad$ PfEtramp5.Ag1 $\quad(P=0.001), \quad$ PfGlurp.R2 $\quad(P=0.007)$, PfMSP1 $_{19}(P<0.001)$, PfRh2 $2030(P<0.001)$, and PfRh5 $(P=0.011)$ (Table 4$)$. The relative magnitude of antibody was greatest in adult individuals ( $\geq 18$ years of age) for all eight of the aforementioned targets with the greatest relative MFIs observed for antibodies against PfMSP $_{19}$ (5.45), PfAMA1 (4.83), Rh2 2030 (4.74) and PfGlurp.R2 (4.72).

The relative magnitude of antibody detected was significantly different across age groups for two of the four $P$. vivax antigens, PvAMA1 $(P=0.020)$ and PvMSP10 $(P=0.002)$. Independent of statistical significance, the relative magnitude of antibody was greatest in the adult 
Table 1 Individual level social and demographic characteristics of study participants in two districts of Meghalaya state, India

\begin{tabular}{|c|c|c|}
\hline Characteristic & $\begin{array}{l}\text { West Jaintia Hills } \\
(\mathrm{N}=1467)\end{array}$ & $\begin{array}{l}\text { West Khasi Hills } \\
(\mathrm{N}=1286)\end{array}$ \\
\hline Age (years)* & $22.2(18.1)$ & $19.2(16.0)$ \\
\hline \multicolumn{3}{|l|}{ Gender } \\
\hline Female & $855(58.3 \%)$ & $697(54.4 \%)$ \\
\hline Male & $612(41.7 \%)$ & $585(45.6 \%)$ \\
\hline \multicolumn{3}{|c|}{ Highest education of participants aged $\geq 18$ years $\wedge$} \\
\hline No formal education & $338(45.7 \%)$ & $160(28.6 \%)$ \\
\hline Below primary (preschool/kindergarten) & $74(10.0 \%)$ & $47(8.4 \%)$ \\
\hline Primary (class V) & $221(29.9 \%)$ & $104(18.6 \%)$ \\
\hline Middle (class VIII) & $48(6.5 \%)$ & $125(22.3 \%)$ \\
\hline Secondary/matric (class X) & $31(4.2 \%)$ & $64(11.4 \%)$ \\
\hline Higher secondary (class XII) & $13(1.8 \%)$ & $34(6.1 \%)$ \\
\hline Graduate & $14(1.9 \%)$ & $25(4.5 \%)$ \\
\hline Post graduate & $0(0 \%)$ & $1(0.2 \%)$ \\
\hline Diploma & $1(0.1 \%)$ & $0(0 \%)$ \\
\hline \multicolumn{3}{|l|}{ Occupation } \\
\hline Cultivator & $349(23.8 \%)$ & $269(20.9 \%)$ \\
\hline Agricultural labourer & $124(8.5 \%)$ & $14(1.1 \%)$ \\
\hline Daily wage/labour & $82(5.6 \%)$ & $76(5.9 \%)$ \\
\hline Salaried service & $28(1.9 \%)$ & $36(2.8 \%)$ \\
\hline Self-employed/trade & $16(1.1 \%)$ & $15(1.2 \%)$ \\
\hline Housewife & $127(8.7 \%)$ & $125(9.7 \%)$ \\
\hline Student & $473(32.3 \%)$ & $512(39.8 \%)$ \\
\hline Child, not schooling & $61(4.2 \%)$ & $28(2.2 \%)$ \\
\hline None & $206(14.1 \%)$ & $205(15.9 \%)$ \\
\hline Other & $0(0 \%)$ & $6(0.5 \%)$ \\
\hline Self-reported malaria in past 12 months & $16(1.1 \%)$ & $83(6.5 \%)$ \\
\hline History of travel in last 14 days & $31(2.1 \%)$ & $25(1.9 \%)$ \\
\hline \multicolumn{3}{|l|}{ Staying in field for one or more night } \\
\hline Yes & $116(7.9 \%)$ & $22(1.7 \%)$ \\
\hline No & $684(46.7 \%)$ & $663(51.6 \%)$ \\
\hline Not applicable & $665(45.4 \%)$ & $600(46.7 \%)$ \\
\hline Number of nights stayed in the field* & $7.3(3.0)$ & $4.8(1.9)$ \\
\hline Taking ITN when staying in the field & 109 (94.0\%) & $10(45.5 \%)$ \\
\hline \multicolumn{3}{|l|}{ Knowledge of signs and symptoms of malaria } \\
\hline Fever & $88(98.9 \%)$ & $315(96.3 \%)$ \\
\hline Headache & $84(94.4 \%)$ & $213(65.3 \%)$ \\
\hline Chill & $68(76.4 \%)$ & $249(85.2 \%)$ \\
\hline Body-ache & $49(55.1 \%)$ & $187(63.8 \%)$ \\
\hline \multicolumn{3}{|l|}{ Preferred healthcare service provider for malaria } \\
\hline Government healthcare facility & $1464(99.8 \%)$ & $1133(88.1 \%)$ \\
\hline Private healthcare facility & $3(0.2 \%)$ & $147(11.4 \%)$ \\
\hline Traditional healer/home management & $0(0 \%)$ & $4(0.3 \%)$ \\
\hline Don't know/other facilities & $0(0 \%)$ & $2(0.2 \%)$ \\
\hline
\end{tabular}

*Mean (SD)

$\wedge$ Only the 740 adult (aged $\geq 18$ years) participants from $\mathrm{JH}$ and 540 adult participants from $\mathrm{KH}$ were included in the analysis 
Table 2 Household level risk factors for Plasmodium infection in two districts of Meghalaya state, India

\begin{tabular}{|c|c|c|c|c|}
\hline & \multicolumn{2}{|c|}{$\begin{array}{l}\text { West Jaintia Hills } \\
(\mathrm{N}=468 \text { households) }\end{array}$} & \multicolumn{2}{|c|}{$\begin{array}{l}\text { West Khasi Hills } \\
(\mathrm{N}=351 \text { households) }\end{array}$} \\
\hline & OR $(95 \% \mathrm{Cl})^{*}$ & $P$-value* & OR $(95 \% \mathrm{Cl})^{*}$ & $P$-value* \\
\hline Presence of electricity & $1.73(0.26-11.69)$ & 0.573 & $1.89(0.40-8.99)$ & 0.424 \\
\hline Presence of mobile phone & $0.53(0.11-2.57)$ & 0.432 & $2.21(0.72-6.81)$ & 0.165 \\
\hline Walls made of mud/thatch/wood^ $\wedge$ & $0.38(0.03-4.86)$ & 0.456 & $0.73(0.25-2.13)$ & 0.563 \\
\hline Roof made of thatch/tile & $-^{\ddagger}$ & $--^{\ddagger}$ & $2.06(0.41-10.40)$ & 0.383 \\
\hline \multicolumn{5}{|l|}{ Presence of animals } \\
\hline Any animal & $1.05(0.25-4.34)$ & 0.949 & $1.89(0.65-5.47)$ & 0.241 \\
\hline Pigs & $1.39(0.32-6.03)$ & 0.661 & $0.80(0.20-3.16)$ & 0.750 \\
\hline Poultry & $2.06(0.49-8.64)$ & 0.323 & $1.10(0.38-3.18)$ & 0.857 \\
\hline Buffalo/cow & $-^{\ddagger}$ & $--^{\ddagger}$ & $3.67(0.37-37.00)$ & 0.269 \\
\hline Animals living inside the house & $0.54(0.12-2.41)$ & 0.421 & $1.33(0.46-3.83)$ & 0.600 \\
\hline Mosquito always present & $0.92(0.22-3.92)$ & 0.913 & $2.23(0.72-6.91)$ & 0.163 \\
\hline Presence of mosquito repellent coils in household & $0.55(0.14-2.16)$ & 0.390 & $2.43(0.80-7.34)$ & 0.115 \\
\hline Presence of mosquito repellent mat tablets in household & $0.50(0.08-3.07)$ & 0.454 & $0.92(0.11-7.79)$ & 0.938 \\
\hline Presence of mosquito repellent vaporizers in household & $2.52(0.44-14.59)$ & 0.301 & $0.94(0.11-8.28)$ & 0.955 \\
\hline \multicolumn{5}{|l|}{ Method for reducing mosquito burden } \\
\hline Insecticide spray & $-{ }^{\ddagger}$ & $--^{\ddagger}$ & $3.48(0.96-12.61)$ & 0.058 \\
\hline Burning neem leaves or cow dung & $-^{\neq}$ & $-{ }_{-}^{\ddagger}$ & $1.00(0.10-10.04)$ & 0.997 \\
\hline Clear bushes around the house & $-^{\ddagger}$ & $-{ }^{\ddagger}$ & $0.62(0.07-5.80)$ & 0.671 \\
\hline Clear stagnant water pools & $-^{\ddagger}$ & $--^{\ddagger}$ & $1.35(0.16-11.36)$ & 0.781 \\
\hline Keep windows/doors closed in evening & $-^{\ddagger}$ & $--^{\ddagger}$ & $0.35(0.06-1.94)$ & 0.228 \\
\hline Screening of windows & $-{ }^{\ddagger}$ & $--^{\ddagger}$ & $1.48(0.36-5.94)$ & 0.582 \\
\hline Presence of chalk markings in house indicating DDT spraying & $-^{\ddagger}$ & $--^{\ddagger}$ & $2.23(0.48-10.30)$ & 0.303 \\
\hline
\end{tabular}

*The OR and $95 \%$ Cls were obtained from multilevel logistic regression models, with Plasmodium positivity at the individual level as the outcome variable, and household and individual level factors as the exposure variables

$\wedge$ Reference category: wall made of brick/concrete/stone

" Reference category: roof made of concrete/tin

${ }^{\ddagger}$ Odds ratio $(95 \% \mathrm{Cl})$ and $P$-value could not be estimated because of separation due to small number of participants with Plasmodium infection

age category for all four $P$. vivax targets with the highest relative MFI observed for PvAMA1 (5.04).

\section{Reported malaria risk-reduction \\ Household level responses}

Questions about presence of mosquitoes and methods for reducing household level human exposure indicated widespread mosquito abundance and extensive efforts to decrease contact (Table 5). Mosquitoes were always (45.4\%) or sometimes (54.5\%) present in essentially every household of both study districts. Nearly every household reported intentionally attempting to reduce mosquito abundance by clearing vegetation (98.2\%) and removing stagnant water around dwellings (97.6\%), as well as keeping windows and doors closed in the evening (97.7\%). The ITNs were universally present (99.3\%), numbering 2 to 3 per household, and were well-maintained by washing (88.8\%). However, the average (SD) age of ITNs was 2.1 (0.5) years. More than two-third of the ITNs (78.6\%) had holes due to wear and tear, most of which $(96.8 \%)$ were repaired. Although roughly half of households (44.5\%) reported sometimes burning insecticide coils indoors, interior walls were sprayed with residual insecticides (IRS) in less than half (46.3\%) of $\mathrm{KH}$ houses and only $6.2 \%$ of dwellings in JH. The commonest reason cited for not spraying walls with the IRS was the spray team not having visited the household (68.2\%), presence of a child (7.7\%) and non-availability of a household member when the spray team visited the household (5.2\%).

\section{Individual level responses}

Individual level anti-mosquito protection was also widespread and appropriate (Table 6). Virtually all individuals (99.4\%) reported sleeping under an ITN regularly (63.4\%) or most of the time (29.7\%). While roughly half of residents (43.1\%) wore clothing to cover arms and legs to reduce mosquito bites, almost none (97.1\%) used insecticidal creams to prevent bites. Evening activities (97.2\%), including dinner (99.7\%), almost always took place inside the house. Essentially everyone (99.8\%) slept inside the 
Table 3 Individual level risk factors for Plasmodium infection of study participants in two districts of Meghalaya state, India

\begin{tabular}{|c|c|c|c|c|}
\hline & \multicolumn{2}{|c|}{$\begin{array}{l}\text { West Jaintia Hills } \\
(\mathrm{N}=1463 \text { Individuals) }\end{array}$} & \multicolumn{2}{|c|}{$\begin{array}{l}\text { West Khasi Hills } \\
\text { ( } N=1234 \text { Individuals) }\end{array}$} \\
\hline & OR $(95 \% \mathrm{Cl})^{*}$ & $P$-value* & OR $(95 \% \mathrm{Cl}) *$ & $P$-value* \\
\hline Age (in years) & $1.01(0.98-1.04)$ & 0.515 & $0.99(0.96-1.02)$ & 0.693 \\
\hline Male sex & $0.45(0.13-1.56)$ & 0.207 & $0.66(0.23-1.84)$ & 0.424 \\
\hline Below primary education^ & $0.65(0.20-2.12)$ & 0.480 & $0.68(0.24-1.89)$ & 0.456 \\
\hline Occupation: Cultivator/Agricultural labourer & $0.89(0.24-3.27)$ & 0.861 & $0.87(0.27-2.86)$ & 0.824 \\
\hline Reported history of malaria in past 12 months & $8.84(1.03-75.15)$ & 0.046 & $-{ }^{\ddagger}$ & $--^{\ddagger}$ \\
\hline Travelled in past 14 days & $--^{\ddagger}$ & $-^{\ddagger}$ & $10.06(1.85-55.68)$ & 0.008 \\
\hline Stayed in field for one or more night(s) & $1.38(0.11-17.06)$ & 0.800 & $4.60(0.47-45.42)$ & 0.192 \\
\hline Knowledge of malaria signs/symptoms & $0.46(0.04-4.83)$ & 0.515 & $0.51(0.11-2.32)$ & 0.381 \\
\hline Leaves house at night to use toilet & $1.05(0.25-4.45)$ & 0.944 & $2.08(0.73-5.89)$ & 0.057 \\
\hline Uses bed net every night & $0.90(0.22-3.72)$ & 0.889 & $1.02(0.26-3.96)$ & 0.978 \\
\hline Never cover arms/legs against mosquitoes & $1.05(0.29-3.84)$ & 0.943 & $0.39(0.13-1.22)$ & 0.106 \\
\hline Uses insecticidal cream against mosquitoes & $-^{\ddagger}$ & $-\neq$ & $0.68(0.08-5.83)$ & 0.726 \\
\hline \multicolumn{5}{|l|}{ Other products used to prevent bites } \\
\hline Mosquito repellent coil & $0.66(0.17-2.60)$ & 0.549 & $1.68(0.56-4.99)$ & 0.351 \\
\hline Mosquito repellent mat tablet & $0.52(0.09-3.16)$ & 0.477 & $-^{\ddagger}$ & $-^{\ddagger}$ \\
\hline Mosquito repellent vaporizer & $2.95(0.50-17.51)$ & 0.233 & $0.71(0.08-6.14)$ & 0.759 \\
\hline Burn other materials & $--^{\ddagger}$ & $-^{\ddagger}$ & $0.92(0.09-9.30)$ & 0.946 \\
\hline Experienced fever in the past $48 \mathrm{~h}$ & $-^{\neq}$ & $-^{\ddagger}$ & $1.17(0.14-9.91)$ & 0.884 \\
\hline
\end{tabular}

*The OR and $95 \%$ Cls were obtained from multilevel logistic regression models, with Plasmodium positivity at the individual level as the outcome variable, and household and individual level factors as the exposure variables

$\wedge$ Individuals with no formal education or completed preschool/ kindergarten

${ }^{\ddagger}$ Odds ratio $(95 \% \mathrm{Cl})$ and $P$-value could not be estimated because of separation due to small number of participants with $P$ lasmodium infection

house, although many (60.5\%) reported leaving the house at night to use the toilet. Early morning activities were reported mostly (81.7\%) to occur inside the house.

\section{Discussion}

This community-based cross-sectional study investigated the prevalence, and household and individual level risk factors of malaria to better understand the epidemiology of Plasmodium infection in the context of ongoing intensive malaria elimination effort in two districts of Meghalaya that only a few years ago had relatively high transmission [10]. A low prevalence of Plasmodium infection in the two communities in 2018 was determined, with malaria prevalence declining to essentially undetectable levels in 2019. Ninety-seven percent of the infected individuals had asymptomatic, sub-microscopic infection, which could only be detected through molecular (PCR-based) methods. A high prevalence of sub-microscopic infections was previously reported from malaria-endemic areas in India [22-24] and elsewhere [25-27]. As sub-microscopic carriers may contribute to sustained transmission of Plasmodium infection [28], the use of molecular diagnostic tools for detection of low-density infections has been recommended for malaria surveillance in low-endemic settings [29].

Plasma samples from a subset of the study participants were analysed for presence of antibodies against thirteen $P$. falciparum and four P. vivax antigens, chosen based upon prior classification as indicators of protection from clinical disease [30] or markers of cumulative exposure or recent infection [31]. The proportion of seropositive individuals, as well as the magnitude of serological response increased with age, which provides further evidence of the decrease in transmission in this area. A positive agedependent seroconversion pattern has previously been reported from areas with low Plasmodium transmission intensity [32-35]. The presence of antibodies to several Plasmodium antigens in children under five years of age, however, can be considered as a marker of relatively recent exposure [36] and provides evidence of continued low-intensity transmission in the area that needs to be monitored.

A history of travel outside of the village within the past 14 days was associated with a higher risk of Plasmodium infection in this study. With increasing movement of people (locally, regionally, and globally), imported malaria from cross-border and regional 
Table 4 Presence and relative magnitude of antibodies to P. falciparum and P. vivax antigens by age in a subset of 264 participants

\begin{tabular}{|c|c|c|c|c|c|c|c|c|}
\hline \multirow[t]{2}{*}{$\begin{array}{l}\text { Antigen/ } \\
\text { Antibody }\end{array}$} & \multicolumn{4}{|c|}{$\begin{array}{l}\text { Number of seropositive individuals } \\
\mathrm{n} \text { (\% of age category) }\end{array}$} & \multicolumn{4}{|c|}{$\begin{array}{l}\text { Relative magnitude of response* } \\
\text { Relative MFI value (IQR) }\end{array}$} \\
\hline & $\begin{array}{l}\text { Age (1-7 years) } \\
(\mathrm{N}=77)\end{array}$ & $\begin{array}{l}\text { Age } \\
(8-17 \text { years }) \\
(\mathrm{N}=72)\end{array}$ & $\begin{array}{l}\text { Age } \\
(\geq 18 \text { years }) \\
(N=115)\end{array}$ & $P$-value^ & Age (1-7 years) & $\begin{array}{l}\text { Age } \\
\text { (8-17 years) }\end{array}$ & $\begin{array}{l}\text { Age } \\
\text { ( } \geq 18 \text { years })\end{array}$ & $P$-value" \\
\hline PfAMA1 & $30(39.0 \%)$ & $31(43.1 \%)$ & $98(85.2 \%)$ & $<0.001$ & $1.21(1.10-1.57)$ & $1.52(1.24-1.69)$ & $4.83(1.92-13.64)$ & $<0.001$ \\
\hline PfEBA140 & $13(16.9 \%)$ & $13(18.1 \%)$ & $63(54.8 \%)$ & $<0.001$ & $2.40(1.53-3.38)$ & $1.86(1.50-2.89)$ & $2.22(1.52-4.60)$ & 0.720 \\
\hline PfEBA175 & $9(11.7 \%)$ & $12(16.7 \%)$ & $82(71.3 \%)$ & $<0.001$ & $1.09(7.35-1.79)$ & $1.86(1.19-2.43)$ & $3.74(2.15-7.45)$ & $<0.001$ \\
\hline PfEBA181 & $6(7.8 \%)$ & $15(20.8 \%)$ & $69(60.0 \%)$ & $<0.001$ & $1.46(1.25-2.75)$ & $1.35(1.19-2.90)$ & $3.65(1.97-6.10)$ & 0.001 \\
\hline PfEtramp5.Ag1 & $12(15.6 \%)$ & $16(22.2 \%)$ & $67(58.3 \%)$ & $<0.001$ & $1.34(1.20-1.94)$ & $1.49(1.12-1.69)$ & $2.25(1.48-4.20)$ & 0.001 \\
\hline PfGlurp.R2 & $5(6.5 \%)$ & $11(15.3 \%)$ & $60(69.6 \%)$ & $<0.001$ & $1.77(1.42-2.17)$ & $1.38(1.08-3.37)$ & $4.72(1.94-10.78)$ & 0.007 \\
\hline PfHSP40.Ag1 & $9(11.7 \%)$ & $9(12.5 \%)$ & $57(49.6 \%)$ & $<0.001$ & $1.43(1.15-2.14)$ & $2.05(1.11-2.15)$ & $1.95(1.43-2.99)$ & 0.077 \\
\hline PfMSP $_{19}$ & $4(5.2 \%)$ & $6(8.3 \%)$ & 91 (79.1\%) & $<0.001$ & $1.50(1.12-2.29)$ & $1.13(1.04-1.25)$ & $5.45(2.70-16.35)$ & $<0.001$ \\
\hline PfMSP2_Ch150 & $3(3.9 \%)$ & $4(5.6 \%)$ & 45 (39.1\%) & $<0.001$ & $1.01,1.02,1.39$ & $1.11(1.09-1.88)$ & $1.49(1.22-2.93)$ & 0.058 \\
\hline PfMSP2_Dd2 & 23 (29.9\%) & $10(13.9 \%)$ & $68(59.1 \%)$ & 0.002 & $2.70(1.36-16.19)$ & $1.91(1.20-2.48)$ & $3.47(1.92-7.71)$ & 0.020 \\
\hline PfRh4.2 & $22(28.6 \%)$ & $20(27.8 \%)$ & $74(64.4 \%)$ & 0.001 & $2.62(1.47-4.66)$ & $2.34(1.72-3.16)$ & $2.21(1.44-4.02)$ & 0.678 \\
\hline PfRh2 2030 & 20 (26.0\%) & $16(22.2 \%)$ & $87(75.7 \%)$ & $<0.001$ & $1.35(1.14-1.86)$ & $1.62(1.25-2.35)$ & $4.74(1.99-9.80)$ & $<0.001$ \\
\hline PfRh5 & 7 (9.1\%) & $14(19.4 \%)$ & $59(51.3 \%)$ & $<0.001$ & $1.15(1.06-2.72)$ & $1.63(1.14-2.11)$ & $2.29(1.40-3.08)$ & 0.011 \\
\hline PvAMA1 & $2(2.6 \%)$ & $3(4.2 \%)$ & $73(63.5 \%)$ & $<0.001$ & $1.19,1.89$ & $2.90(1.25-3.28)$ & $5.04(2.32-14.26)$ & 0.020 \\
\hline PvMSP10 & $28(38.4 \%)$ & $24(33.3 \%)$ & 94 (81.7\%) & $<0.001$ & $1.57(1.29-2.11)$ & $1.43(1.19-2.93)$ & $2.47(1.45-4.06)$ & 0.002 \\
\hline $\mathrm{PVMSP}_{19}$ & $2(2.6 \%)$ & $4(5.6 \%)$ & $58(50.4 \%)$ & $<0.001$ & $1.36,2.14$ & $1.61(1.43-1.93)$ & $2.18(1.50-5.10)$ & 0.218 \\
\hline PVMSP8 & $22(28.6 \%)$ & $28(38.9 \%)$ & 92 (80.0\%) & $<0.001$ & $1.83(1.16-2.60)$ & $1.75(1.39-3.03)$ & $2.02(1.40-3.31)$ & 0.164 \\
\hline
\end{tabular}

*Only seropositive individuals were included in the analysis of each antigen

$\wedge$ Chi-square test for trend for difference in the proportion of seropositive individuals across age categories ( $1-7$ years; $8-17$ years; $\geq 18$ years)

" Non-parametric test for trend for the difference in the magnitude of response in seropositive individuals across age categories (1-7 years; $8-17$ years; $\geq 18$ years)

human movement represents a major obstacle to malaria elimination [37, 38], especially in NE India [9] that shares vast international borders with five countries, including Bangladesh, Myanmar and Bhutan, all of which are malaria-endemic countries [1]. This highlights the need for strict vigilance of the border areas to prevent reintroduction of malaria in the post-elimination era.

A reported history of malaria in the past 12 months was associated with a higher risk of $P$. falciparum infection in this study. Recurrent episodes of malaria occurring in a small percentage of individuals have earlier been reported from endemic areas [39-41]. In a longitudinal study from Kenya, $21 \%$ of participants were found to contribute to $55 \%$ of the clinical malaria cases in that population [42]. Mathematical models have demonstrated an over-dispersion in the prevalence of malaria, which is generally considered to follow the ' $80 / 20$ ' rule, i.e., $80 \%$ of infections occur in $20 \%$ of the population [43, 44]. The reasons for this over-dispersion are not fully established and are attributed to a combination of host (such as human genetics and behaviour) [45-47] and environmental factors (such as distance from mosquito breeding area, wind pattern and exposure to infectious mosquitoes) $[41,45,48]$.
Virtually every participant in the present study reported using ITNs. In a recent meta-analysis, ITN use was associated with $45 \%$ and $39 \%$ reduction in incidence of uncomplicated episodes of P. falciparum and P. vivax malaria, respectively [49]. In another meta-analysis study, ITNs were found to be more effective than untreated bed-nets regardless of insecticide resistance, although substantial heterogeneity between studies was noted [50]. Also, nearly every household reported that holes in ITNs were repaired. In a cohort study in Malawi with consistently high ITN usage, use of nets without holes conferred significantly greater protection than using nets with holes, despite moderate levels of insecticide resistance [51].

Indoor residual spray coverage in the study districts was low, with only $23 \%$ of the households reported having been sprayed in the preceding 12 months, much less than the World Health Organization target of $>85 \%$ IRS coverage for preventing malaria transmission [52]. Low levels of IRS coverage have been reported by other studies conducted in India [53,54] and elsewhere [55], and is attributed to various factors such as lack of knowledge about IRS benefits, spray operators' behaviours, resident's reluctance to remove household items, and preference for using ITNs $[54,56,57]$. The present study found 
Table 5 Household level mosquito risk and prevention methods in 820 households from two districts of Meghalaya state, India

\begin{tabular}{lll}
\hline Characteristic & West Jaintia & West \\
& Hills $(N=468)$ & Khasi Hills \\
& $(N=352)$
\end{tabular}

Mosquitoes present in house

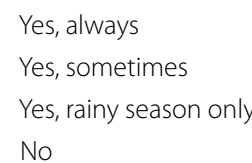

Methods used to reduce mosquitoes

Clear bushes around the house

Clear stagnant water pools

Keeping windows/doors closed in evening

Screening of windows

Insecticide spray

Use larvicide in ponds

Burn other materials

ITN presence, condition, treatment

Any ITNs present in house

Number of ITNs present: Median (IQR)*

Duration (years) of ITN use: Mean (SD)*

Washing of ITN by HH members*

Wash frequency: Median (IQR)^

Holes/defects in ITN*

Repair of holes/defects in ITN"

DDT spraying by NVBDCP ( $\mathrm{HH}$ marked)

IRS spraying of house ( $<12$ months)

Yes

No

Don't know

$\begin{array}{cl}263(56.2 \%) & 109(31.0 \%) \\ 125(26.7 \%) & 102(29.0 \%) \\ 80(17.1 \%) & 140(39.7 \%) \\ 0(0 \%) & 1(0.3 \%)\end{array}$

$\begin{aligned} 467(99.8 \%) & 337(96.0 \%) \\ 466(99.6 \%) & 333(94.8 \%) \\ 467(99.8 \%) & 334(94.9 \%) \\ 10(2.1 \%) & 147(42.0 \%) \\ 2(0.4 \%) & 20(5.7 \%) \\ 2(0.4 \%) & 3(0.9 \%) \\ 3(0.6 \%) & 45(12.8 \%)\end{aligned}$

$466(99.6 \%)$

$343(98.9 \%)$

$2(2-3)$

$3(2-3)$

$2.0(0.2)$

$463(99.4 \%)$

$2.2(0.8)$

4 (3-4)

$260(74.9 \%)$

$400(86.2 \%)$

$392(98.0 \%)$

$2(2-3)$

$233(68.3 \%)$

$25(5.3 \%)$

$221(94.9 \%)$

$117(49.4 \%)$

$29(6.2 \%) \quad 163(46.3 \%)$

$439(93.8 \%)$

$181(51.4 \%)$

$0(0 \%)$

Reason for not using IRS in house

Spray team did not visit the household

Presence of children

Not at home at the time of spraying

Don't like the smell

Stains the walls

Dangerous for silk production

Mosquito repellent coils present in house

Time of day coils used in house ${ }^{\ddagger}$

$\begin{array}{lcl}\text { Night time } & 162(61.4 \%) & 62(61.4 \%) \\ \text { Evening } & 157(59.5 \%) & 51(50.5 \%) \\ \text { Daytime } & 0(0 \%) & 0(0 \%)\end{array}$

Frequency of mosquito repellent coil use $\mathrm{e}^{\ddagger}$

\begin{tabular}{lcl} 
Always & $21(8.0 \%)$ & $25(25.3 \%)$ \\
Sometimes & $242(92.0 \%)$ & $72(72.7 \%)$ \\
Rarely & $0(0 \%)$ & $2(2.0 \%)$ \\
\hline
\end{tabular}

*For the households reporting presence of ITN

$\wedge$ For the households reporting washing of ITN

" For the households reporting holes/defects in ITN

${ }^{\ddagger}$ For the households reporting presence of coils

$391(89.1 \%) \quad 32(17.7 \%)$

$14(3.2 \%) \quad 34(18.8 \%)$

$10(2.3 \%)$

$22(12.2 \%)$

$16(3.6 \%)$

$1(0.2 \%)$

$9(2.1 \%)$

$22(12.2 \%)$

$10(5.5 \%)$

$0(0 \%)$

$264(56.4 \%)$

$101(28.7 \%)$
Table 6 Individual level mosquito risk and prevention methods among 2,753 study participants from two districts of Meghalaya state, India

\section{Characteristic}

Hills $(\mathrm{N}=1467) \quad$ Khasi Hills

$(\mathrm{N}=1286)$

Generally, sleep under bed net at night

If yes, bed net treated with insecticide

Yes

No

$\begin{array}{cc}1467(100 \%) & 1270(98.8 \%) \\ 1457(99.4 \%) & 1245(98.1 \%) \\ 7(0.5 \%) & 24(1.9 \%) \\ 738(50.3 \%) & 998(78.5 \%) \\ 724(49.4 \%) & 90(7.1 \%) \\ 4(0.3 \%) & 36(2.8 \%) \\ 0(0 \%) & 3(0.2 \%) \\ 1(0.1 \%) & 142(11.2 \%) \\ 1456(99.3 \%) & 1247(97.2 \%) \\ & \\ 19(1.3 \%) & 169(13.1 \%) \\ 770(52.5 \%) & 229(17.8 \%) \\ 6(0.4 \%) & 155(12.1 \%) \\ 672(45.8 \%) & 733(57.0 \%) \\ & \\ 5(0.3 \%) & 11(0.8 \%) \\ 16(1.1 \%) & 25(1.9 \%) \\ 4(0.3 \%) & 18(1.4 \%) \\ 1442(98.3 \%) & 1232(95.8 \%)\end{array}$

If yes, frequency of bed net use

Every night

Most of the times

Sometimes

Rarely

Only in rainy season

Used bed net preceding night

Cover arms/legs to prevent bites

Always

Sometimes

Rarely

Never

Use insecticidal creams to prevent bites

Always
Sometimes
Rarely
Never

Other products used to prevent bites

Mosquito repellent coil

$806(54.9 \%) \quad 377(29.3 \%)$

Mosquito repellent mat tablet

$105(7.2 \%)$

$89(6.9 \%)$

Mosquito repellent vaporizer

$51(3.4 \%)$

$53(4.1 \%)$

Burn other materials

Dinner eaten inside the house

Location of activities before sleeping

Inside the house

Outside the house

Depends on conditions

Sleeping location

Inside the house

Outside the house

Depends on conditions

Leave house at night to use toilet

Location of early morning activities*

Inside the house

Outside the house

Location depending on season

$20(1.4 \%)$

$158(12.3 \%)$

1467 (100\%)

$1284(99.9 \%)$

$1402(95.6 \%) \quad 1270(99.0 \%)$

$60(4.1 \%) \quad 11(0.9 \%)$

$5(0.3 \%) \quad 2(0.2 \%)$

$\begin{array}{cc}1465(99.9 \%) & 1280(99.6 \%) \\ 1(0.1 \%) & 2(0.2 \%) \\ 1(0.1 \%) & 3(0.2 \%) \\ 1089(74.2 \%) & 576(44.9 \%) \\ & \\ 325(72.5 \%) & 691(86.9 \%) \\ 98(21.9 \%) & 89(11.2 \%) \\ 24(5.4 \%) & 5(0.6 \%) \\ 1(0.2 \%) & 11(0.9 \%)\end{array}$

*Data available for 448 individuals in $\mathrm{JH}$ and 795 individuals in $\mathrm{KH}$ 
that the main reasons for low IRS coverage were that the spray team did not visit, an adult household member was not present when the spray team visited, refusal due to the presence of children or the dislike of the IRS smell. With increasing concern over reduced effectiveness of LLINs due to pyrethroid resistance [58-60], increasing the IRS coverage and acceptability through community participation [61] may be needed to sustain the gains in malaria elimination in endemic settings.

The lack of understanding of what causes malaria, the use of ineffective prevention methods, the belief that malaria cannot be prevented, and general reliance on traditional remedies have been cited as major barriers to malaria prevention and treatment [62]. In Meghalaya, most study participants were knowledgeable of malaria symptoms, regularly practiced appropriate malaria prevention, and sought treatment in a government healthcare facility. These findings are also consistent with the decrease in transmission and partly explain the difficulty in identifying risk factors associated with positive infection status.

Despite enrolling more than 2500 participants, the low prevalence of Plasmodium-positive individuals resulted in reduced statistical power to evaluate the risk factors for infection in this population, which is a limitation of this study. Future studies in low-transmission settings may consider including serological markers of recent infection as a tool to estimate the burden and transmission patterns of malaria in low-intensity settings [25, 63]. As with all community-based studies, the individuals participating in the cross-sectional survey may not be a representative sample of the study population (Fig. 2), possibly because of out-migration for employment or education. As migrants are considered to be at higher risk of malaria, especially if travelling to malariaendemic areas $[64,65]$, the overall Plasmodium infection prevalence may have been underestimated in this study. Finally, detailed exposure history could not be obtained for participants with serology results, which limited the ability to differentiate between recent and long-term exposure to Plasmodium infection.

\section{Conclusion}

This study provides important insights into the epidemiology of malaria in a low-transmission setting in India. The high proportion of asymptomatic Plasmodium infections and the presence of anti-Plasmodium antibodies detected in children under five years of age suggests "hidden" transmission in the region, although the relative contribution of asymptomatic and submicroscopic individuals to parasite transmission and/ or clinical malaria in low-transmission settings need to be explored further. The higher infection risk observed among those with a travel history in a region with extensive international borders, heterogeneous distribution of Plasmodium infections, abundant vector populations, and favourable environmental conditions $[9,11]$ altogether highlight the importance of constant vigilance to counter the threat of malaria resurgence from imported cases. Periodic serological surveys may be considered to monitor temporal trends in malaria transmission and to monitor progress towards elimination $[32,66]$. Considering the widespread ITN usage among the study participants, monitoring for insecticide resistance should be undertaken to ensure continued effectiveness of vector-control methods.

\begin{abstract}
Acknowledgements
We are indebted to the study participants for their enthusiastic participation and support. We thank the Department of Health and Family Welfare, Government of Meghalaya and the Meghalaya State Programme Management Unit, National Vector-Borne Disease Control Programme for providing permission to carry out this study, and for their active support and collaboration. We acknowledge the support of Anna Maria van Eijk for her help with the cross-sectional survey design and Badondor Shylla for his help with the project management. We thank the IIPH-Shillong staff, specifically Phibansuk Lyngdoh, Christine Manar, Manroi Challam, Enrichson Suting, Watson Siangshai, Jurysha Nongdhar, Charisma Khongwir, and Peter Marbaniang for their help with the survey data and sample collection, and Zachariah Sunn and Innang Sangniang for their role in the laboratory work. We also thank New York University MPH student Natsumi Nemoto for support with sample quality control and repeating concentrated PCRs.
\end{abstract}

\section{Authors' contributions}

AK, SA, SAS and JC conceived and designed the active surveillance study and undertook the data collection; RS and MLW cleaned the data and performed the data analyses; BK completed the DNA extractions and PCR amplifications for the active surveillance study; AK performed the antibody assays; RS, MLW, $A K$, and SA wrote the manuscript with input from all authors. All authors read and approved the final manuscript.

\section{Funding}

Research reported in this publication was supported by the National Institute of Allergy and Infectious Diseases of the National Institutes of Health under Award Number U19A1089676 as part of the International Centers of Excellence for Malaria Research. The content is solely the responsibility of the authors and does not necessarily represent the official views of the National Institutes of Health.

\section{Availability of data and materials}

Data generated in this study are available through the open-access online resource for population-based epidemiological studies ClinEpiDB (https://cline pidb.org) at https://clinepidb.org/ce/app/record/dataset/DS_4670e06911.

\section{Declarations}

\section{Ethics approval and consent to participate}

Ethical approval for the study was obtained from the Institutional Review Boards (IRBs) of Martin Luther Christian University, Shillong, Meghalaya, India and New York University, New York, NY, USA. Written informed consent was obtained from all the participants who were 18 years of age or older. Assent was obtained for the participants aged $7-18$ years in addition to parental consent.

\section{Consent for publication}

Not applicable.

Competing interests

The authors declare that they have no competing interests. 


\section{Author details}

${ }^{1}$ Indian Institute of Public Health - Shillong, Shillong, Meghalaya 793001, India. ${ }^{2}$ Martin Luther Christian University, Shillong, Meghalaya 793006, India. ${ }^{3}$ Center for Genomics and Systems Biology, Department of Biology, New York University, New York, NY 10003, USA. ${ }^{4}$ Department of Epidemiology, School of Public Health, University of Michigan, Ann Arbor, MI 48109, USA. ${ }^{5}$ Department of Epidemiology, School of Global Public Health, New York University, New York, NY 10003, USA.

Received: 28 August 2021 Accepted: 12 November 2021

Published online: 11 December 2021

\section{References}

1. WHO. World Malaria Report: 20 years of global progress and challenges. Geneva: World Health Organization; 2020.

2. Guerin PJ, Dhorda M, Ganguly NK, Sibley CH. Malaria control in India: a national perspective in a regional and global fight to eliminate malaria. J Vector Borne Dis. 2019;56:41-5.

3. Sarma DK, Mohapatra PK, Bhattacharyya DR, Chellappan S, Karuppusamy B, Barman K, et al. Malaria in North-East India: importance and implications in the era of elimination. Microorganisms. 2019;7:673.

4. National Vector Borne Disease Control Programme (NVBDCP). National Framework for Malaria Elimination in India (2016-2030). 2016: Ministry of Health and Family Welfare, Government of India.

5. National Vector Borne Disease Control Programme (NVBDCP). National Strategic Plan. Malaria Elimination in India. 2017-2022. New Delhi: Ministry of Health and Family Welfare. Government of India; 2017.

6. Dhiman S. Are malaria elimination efforts on right track? An analysis of gains achieved and challenges ahead. Infect Dis Poverty. 2019;8:14.

7. Nema S, Ghanghoria P, Bharti PK. Malaria elimination in India: bridging the gap between control and elimination. Indian Pediatr. 2020;57:613-7.

8. Wangdi K, Gatton ML, Kelly GC, Banwell C, Dev V, Clements ACA. Malaria elimination in India and regional implications. Lancet Infect Dis. 2016;16:e214-24.

9. Dev $V$, Manguin S. Defeating malaria in the North-East region: the forerunner for malaria elimination in India. Acta Trop. 2021;222:106040.

10. Kessler A, van Eijk AM, Jamir L, Walton C, Carlton JM, Albert S. Malaria in Meghalaya: a systematic literature review and analysis of data from the National Vector-Borne Disease Control Programme. Malar J. 2018;17:411.

11. Kessler A, Shylla B, Singh US, Lyngdoh R, Mawkhlieng B, van Eijk AM, et al. Spatial and temporal village-level prevalence of Plasmodium infection and associated risk factors in two districts of Meghalaya. India Malar J. 2021;20:70.

12. Office of the Registrar General and Census Commissioner, India: Census of India 2011. Meghalaya Profile. Census Info India 2011. https://censusindia.gov.in/2011 census/censusinfodashboard/stock/profiles/en/IND017 Meghalaya.pdf. Accessed 04 Nov 2021.

13. Forest and Environment Department, Government of Meghalaya. Forest Cover. http://www.megforest.gov.in/forest_cover.html. Accessed $04 \mathrm{Nov}$ 2021.

14. Feroze SM, Raju VT, Singh R, Tripathi AK. Status of livestock sector: a micro study of North Eastern India. Ind J Hill Farming. 2010;23:43-51.

15. Demas A, Oberstaller J, DeBarry J, Lucchi NW, Srinivasamoorthy G, Sumari D, et al. Applied genomics: data mining reveals species-specific malaria diagnostic targets more sensitive than 18S rRNA. J Clin Microbiol. 2011;49:2411-8

16. Ompad DC, Kessler A, Van Eijk AM, Padhan TK, Haque MA, Sullivan SA, et al. The effectiveness of malaria camps as part of the Durgama Anchalare Malaria Nirakaran (DAMaN) program in Odisha, India: study protocol for a cluster-assigned quasi-experimental study. Glob Health Action. 2021;14:1886458.

17. Wu L, Hall T, Ssewanyana I, Oulton T, Patterson C, Vasileva H, et al. Optimisation and standardisation of a multiplex immunoassay of diverse Plasmodium falciparum antigens to assess changes in malaria transmission using sero-epidemiology. Wellcome Open Res. 2019;4:26.

18. Harris PA, Taylor R, Minor BL, Elliott V, Fernandez M, O'Neal L, et al. The REDCap consortium: building an international community of software platform partners. J Biomed Inform. 2019;95:103208.
19. Harris PA, Taylor R, Thielke R, Payne J, Gonzalez N, Conde JG. Research electronic data capture (REDCap)-a metadata-driven methodology and workflow process for providing translational research informatics support. J Biomed Inform. 2009;42:377-81.

20. Valliant R. A survey on survey statistics: what is done and can be done in stata. Stata J. 2007;7:1-21.

21. Cuzick J. A Wilcoxon-type test for trend. Stat Med. 1985:4:87-90.

22. Kaura T, Kaur J, Sharma A, Dhiman A, Pangotra M, Upadhyay AK, et al. Prevalence of submicroscopic malaria in low transmission state of Punjab: a potential threat to malaria elimination. J Vector Borne Dis. 2019;56:78-84

23. Kumari P, Sinha S, Gahtori R, Yadav CP, Pradhan MM, Rahi M, et al. Prevalence of asymptomatic malaria parasitemia in Odisha, India: a challenge to malaria elimination. Am J Trop Med Hyg. 2020;103:1510-6.

24. van Eijk AM, Sutton PL, Ramanathapuram L, Sullivan SA, Kanagaraj D, Priya GSL, et al. The burden of submicroscopic and asymptomatic malaria in India revealed from epidemiology studies at three varied transmission sites in India. Sci Rep. 2019;9:17095.

25. Edwards HM, Dixon R, Zegers de Beyl C, Celhay O, Rahman M, Myint Oo $\mathrm{M}$, et al. Prevalence and seroprevalence of Plasmodium infection in Myanmar reveals highly heterogeneous transmission and a large hidden reservoir of infection. PLOS ONE. 2021;16:e0252957.

26. Motshoge T, Haiyambo DH, Ayanful-Torgby R, Aleksenko L, Ntebela D, Malleret $B$, et al. Recent molecular assessment of Plasmodium vivax and Plasmodium falciparum asymptomatic infections in Botswana. Am J Trop Med Hyg. 2021;104:2159-64.

27. Tadesse FG, Slater HC, Chali W, Teelen K, Lanke K, Belachew M, et al. The relative contribution of symptomatic and asymptomatic Plasmodium vivax and Plasmodium falciparum infections to the infectious reservoir in a low-endemic setting in Ethiopia. Clin Infect Dis. 2018;66:1883-91.

28. Okell LC, Bousema T, Griffin JT, Ouedraogo AL, Ghani AC, Drakeley CJ. Factors determining the occurrence of submicroscopic malaria infections and their relevance for control. Nat Commun. 2012;3:1237.

29. Bousema T, Okell L, Felger I, Drakeley C. Asymptomatic malaria infections: detectability, transmissibility and public health relevance. Nat Rev Microbiol. 2014;12:833-40.

30. Osier FH, Polley SD, Mwangi T, Lowe B, Conway DJ, Marsh K. Naturally acquired antibodies to polymorphic and conserved epitopes of Plasmodium falciparum merozoite surface protein 3. Parasite Immunol. 2007:29:387-94.

31. Elliott SR, Fowkes FJ, Richards JS, Reiling L, Drew DR, Beeson JG. Research priorities for the development and implementation of serological tools for malaria surveillance. F1000Prime Rep. 2014;6:100.

32. Idris ZM, Chan CW, Mohammed M, Kalkoa M, Taleo G, Junker K, et al. Serological measures to assess the efficacy of malaria control programme on Ambae Island. Vanuatu Parasit Vectors. 2017;10:204

33. Keffale M, Shumie G, Behaksra SW, Chali W, Hoogen L, Hailemeskel E, et al. Serological evidence for a decline in malaria transmission following major scale-up of control efforts in a setting selected for Plasmodium vivax and Plasmodium falciparum malaria elimination in Babile district, Oromia, Ethiopia. Trans R Soc Trop Med Hyg. 2019;113:305-11.

34. Stewart L, Gosling R, Griffin J, Gesase S, Campo J, Hashim R, et al. Rapid assessment of malaria transmission using age-specific sero-conversion rates. PLoS ONE. 2009;4:e6083.

35. Zakeri S, van den Hoogen LL, Mehrizi AA, Karimi F, Raeisi A, Drakeley C. Anti-malarial seroprevalence assessment during an elimination programme in Chabahar District, south-eastern Iran. Malar J. 2016;15:382.

36. Biggs J, Raman J, Cook J, Hlongwana K, Drakeley C, Morris N, et al. Serology reveals heterogeneity of Plasmodium falciparum transmission in northeastern South Africa: implications for malaria elimination. Malar J. 2017; $16: 48$

37. Liu Y, Sturrock HJW, Yang H, Gosling RD, Cao J. The challenge of imported malaria to eliminating countries. Lancet Infect Dis. 2017;17:141.

38. Sturrock HJW, Roberts KW, Wegbreit J, Ohrt C, Gosling RD. Tackling imported malaria: an elimination endgame. Am J Trop Med Hyg. 2015;93:139-44.

39. Kotepui M, Punsawad C, Kotepui KU, Somsak V, Phiwklam N, PhunPhuech B. Prevalence of malarial recurrence and hematological alteration following the initial drug regimen: a retrospective study in Western Thailand. BMC Public Health. 2019;19:1294. 
40. Lawpoolsri S, Sattabongkot J, Sirichaisinthop J, Cui L, Kiattibutr K, Rachaphaew N, et al. Epidemiological profiles of recurrent malaria episodes in an endemic area along the Thailand-Myanmar border: a prospective cohort study. Malar J. 2019;18:124.

41. Rono J, Farnert A, Murungi L, Ojal J, Kamuyu G, Guleid F, et al. Multiple clinical episodes of Plasmodium falciparum malaria in a low transmission intensity setting: exposure versus immunity. BMC Med. 2015;13:114

42. Mwangi TW, Fegan G, Williams TN, Kinyanjui SM, Snow RW, Marsh K. Evidence for over-dispersion in the distribution of clinical malaria episodes in children. PLOS ONE. 2008:3:e2196.

43. Smith DL, Dushoff J, Snow RW, Hay SI. The entomological inoculation rate and Plasmodium falciparum infection in African children. Nature. 2005:438:492-5.

44. Woolhouse ME, Dye C, Etard JF, Smith T, Charlwood JD, Garnett GP, et al. Heterogeneities in the transmission of infectious agents: implications for the design of control programs. Proc Natl Acad Sci USA. 1997;94:338-42.

45. ClarkTD, Greenhouse B, Njama-Meya D, Nzarubara B, Maiteki-Sebuguzi C, Staedke SG, et al. Factors determining the heterogeneity of malaria incidence in children in Kampala, Uganda. J Infect Dis. 2008;198:393-400.

46. Kreuels B, Kobbe R, Adjei S, Kreuzberg C, von Reden C, Bater K, et al. Spatial variation of malaria incidence in young children from a geographically homogeneous area with high endemicity. J Infect Dis. 2008;197:85-93.

47. Goncalves BP, Kapulu MC, Sawa P, Guelbeogo WM, Tiono AB, Grignard $L$, et al. Examining the human infectious reservoir for Plasmodium falciparum malaria in areas of differing transmission intensity. Nat Commun. 2017;8:1133.

48. Cooper L, Kang SY, Bisanzio D, Maxwell K, Rodriguez-Barraquer I, Greenhouse $B$, et al. Pareto rules for malaria super-spreaders and super-spreading. Nat Commun. 2019;10:3939.

49. Pryce J, Richardson M, Lengeler C. Insecticide-treated nets for preventing malaria. Cochrane Database Syst Rev. 2018;11:CD000363.

50. Strode C, Donegan S, Garner P, Enayati AA, Hemingway J. The impact of pyrethroid resistance on the efficacy of insecticide-treated bed nets against African anopheline mosquitoes: systematic review and metaanalysis. PLoS Med. 2014;11:e1001619.

51. Shah MP, Steinhardt LC, Mwandama D, Mzilahowa T, Gimnig JE, Bauleni $A$, et al. The effectiveness of older insecticide-treated bed nets (ITNs) to prevent malaria infection in an area of moderate pyrethroid resistance: results from a cohort study in Malawi. Malar J. 2020;19:24.

52. WHO. Indoor residual spraying: an operational manual for indoor residual spraying (IRS) for malaria transmission control and elimination. 2nd ed. Geneva: World Health Organization; 2015.

53. Prasad $\mathrm{H}$. Evaluation of malaria control programme in three selected districts of Assam. India J Vector Borne Dis. 2009;46:280-7.

54. Singh RK, Das MK, Dhiman RC, Mittal PK, Dua VK, Sreehari U, et al. Evaluation of indoor residual spray and insecticide treated bed nets in a malaria endemic area of Santhal Pargana, Dumka district (Jharkhand). J Commun Dis. 2012;44:169-79.

55. Tangena JA, Hendriks CMJ, Devine M, Tammaro M, Trett AE, Williams I, et al. Indoor residual spraying for malaria control in sub-Saharan Africa 1997 to 2017: an adjusted retrospective analysis. Malar J. 2020;19:150.

56. Magaco A, Botao C, Nhassengo P, Saide M, Ubisse A, Chicumbe S, et al. Community knowledge and acceptance of indoor residual spraying for malaria prevention in Mozambique: a qualitative study. Malar J. 2019;18:27.

57. Suuron VM, Mwanri L, Tsourtos G, Owusu-Addo E. An exploratory study of the acceptability of indoor residual spraying for malaria control in upper western Ghana. BMC Public Health. 2020;20:465.

58. Churcher TS, Lissenden N, Griffin JT, Worrall E, Ranson H. The impact of pyrethroid resistance on the efficacy and effectiveness of bednets for malaria control in Africa. Elife. 2016;5:e16090

59. Hemingway J, Ranson H, Magill A, Kolaczinski J, Fornadel C, Gimnig J, et al. Averting a malaria disaster: will insecticide resistance derail malaria control? Lancet. 2016;387:1785-8.

60. Sherrard-Smith E, Griffin JT, Winskill P, Corbel V, Pennetier C, Djenontin A, et al. Systematic review of indoor residual spray efficacy and effectiveness against Plasmodium falciparum in Africa. Nat Commun. 2018;9:4982

61. Rodriguez MH. Residual malaria: limitations of current vector control strategies to eliminate transmission in residual foci. J Infect Dis. 2021;223(Supplement_2):S55-S60.
62. Maslove DM, Mnyusiwalla A, Mills EJ, McGowan J, Attaran A, Wilson K. Barriers to the effective treatment and prevention of malaria in Africa: a systematic review of qualitative studies. BMC Int Health Hum Rights. 2009;9:26.

63. Bousema T, Youssef RM, Cook J, Cox J, Alegana VA, Amran J, et al. Serologic markers for detecting malaria in areas of low endemicity, Somalia, 2008. Emerg Infect Dis. 2010;16:392-9.

64. Alemu K, Worku A, Berhane Y, Kumie A. Men traveling away from home are more likely to bring malaria into high altitude villages, northwest Ethiopia. PLoS ONE. 2014;9:e95341.

65. Saita S, Pan-Ngum W, Phuanukoonnon S, Sriwichai P, Silawan T, White LJ, et al. Human population movement and behavioural patterns in malaria hotspots on the Thai-Myanmar border: implications for malaria elimination. Malar J. 2019;18:64.

66. Perraut R, Varela ML, Loucoubar C, Niass O, Sidibe A, Tall A, et al. Serological signatures of declining exposure following intensification of integrated malaria control in two rural Senegalese communities. PLOS ONE. 2017;12:e0179146.

\section{Publisher's Note}

Springer Nature remains neutral with regard to jurisdictional claims in published maps and institutional affiliations.

Ready to submit your research? Choose BMC and benefit from:

- fast, convenient online submission

- thorough peer review by experienced researchers in your field

- rapid publication on acceptance

- support for research data, including large and complex data types

- gold Open Access which fosters wider collaboration and increased citations

- maximum visibility for your research: over 100M website views per year

At BMC, research is always in progress.

Learn more biomedcentral.com/submissions 